\title{
An Empirical Research on the Influencing Factors of New Energy Talents Attraction in Shanghai, China
}

\author{
Wang Yinlong \\ School of Economics, Shanghai University, Shanghai, China
}

\section{Email address:}

mynamedragon@126.com

\section{To cite this article:}

Wang Yinlong. An Empirical Research on the Influencing Factors of New Energy Talents Attraction in Shanghai, China. Science Innovation. Vol. 5, No. 2, 2017, pp. 117-121. doi: 10.11648/j.si.20170502.19

Received: March 31,2017; Accepted: April 17, 2017; Published: April 20, 2017

\begin{abstract}
With the development of the times, the competition of comprehensive national strength is the competition of talents. The attraction of scientific and technological talents has become the focus of national or regional studies. Based on the investigation of Shanghai, China, the new energy industry, at the three level (regional level, industry level and enterprise level) investigation of the new energy industry attraction to talent in science and technology, and the result of the empirical analysis by using SPSS. Then combined with the results of the questionnaire was verified by the method of statistical analysis, summarized the important factors influencing the technological talent attraction including regional level, industry level and enterprise level, finally according to the above results and put forward policy recommendations.
\end{abstract}

Keywords: New Energy Talents, Attractive Force, Questionnaire

\section{中国上海市新能源人才吸引力影响因素的实证研究}

\author{
王寅龙 \\ 经济学院, 上海大学, 上海, 中国 \\ 邮箱 \\ mynamedragon@126.com
}

摘要：随着时代的发展, 综合国力的竞争就是人才的竞争。对于科技人才的吸引成为了国家或地区研究的重点。本文 通过对中国上海新能源行业的调研，在三个层面上（地区层面、行业层面、企业层面）调查了新能源行业对科技人才 的吸引力, 并利用spss软件对调查结果进行了实证分析。然后结合问卷结果利用统计分析方法对其进行了验证, 概括 出包括地区层面、行业层面、企业层面在内的影响科技人才吸引力的重要因素, 最后据此验证结果并提出了政策建议。

关键词: 新能源人才, 吸引力, 调查问卷

\section{1. 引言}

当今世界的发展中, 国家之间的竞争愈演愈烈, 国 与国之间的较量主要是综合国力的竞争，而综合国力的 竞争说到底就是人才的竞争。因此, 对优秀科技人才的 吸引也成为各个国家发展战略的首要举措。作为当今世
界上最大的发展中国家，中国现阶段对人才的渴求比历 史上任何时期都要强烈。同样，一个国家或地区要想获 得竞争优势, 能否取得与其发展相适应的人才资源是非 常重要的, 而获得相当的人才资源取决于该国家或地区 对人才的吸引力是否足够。在吸引人才的过程中, 地区、 行业、企业都是有影响力的载体, 科学认识和评价这些 
载体对吸引人才的作用, 对于人才资源的利用有着重要 的意义 $[1]$ 。

上海市作为中国重要的经济、交通、科技、工业、 金融、会展和航运中心，拥有得天独厚的地理、文化优 势。在 20 世纪以来, 上海就一直作为中国的领军城市带 动中国的经济发展, 在吸引人才方面具有天然的优势。 新能源行业作为一个新兴行业, 在能源利用和环境保护 方面具有相对较大的优势, 因此该行业也逐渐成为政府 所庇护、科技人才所流向的行业。本文将通过对上海市 的新能源行业进行调查, 对于影响科技人才选择新能源 行业的影响因素进行分析, 为完善上海市吸引科技人才 政策, 对科创中心提供人才支持, 以及促进上海市更好 更健康发展提供理论依据 [6]。

\section{2. 理论构建与研究假设}

\section{1. 理论建构}

\subsection{1. 新能源人才吸引力的界定}

新能源人才吸引力根据层次不同可以分为地区对科 技人才的吸引力、行业对科技人才吸引力以及企业对科 技人才的吸引力三部分。而且在调查时, 通过科研人员 本身, 管理层人员以及企业总监三个级别对新能源行业 人才吸引力影响因素进行界定。

\subsection{2. 本文的理论分析框架}

新能源人才吸引力的影响因素主要为地区层面吸引 力、行业层面吸引力和企业层面吸引力。从影响因素的 层级内看, 地区层面吸引力包括地区的自然环境影响、 生活环境影响、文化环境影响和人才政策的影响等。行 业层面吸引力包括行业薪酬福利影响、行业政府扶持影 响和行业发展前景影响等。企业层面吸引力包括企业福 利影响、企业科研条件影响、企业激励体系影响、企业 管理风格影响、企业工作特征影响、企业发展前途影响 等。通过以上三个层面来分析对新能源人才吸引力的影 响因素。

\section{2. 新能源行业人才吸引力的影响因素分析及研究假设}

2.2.1.地区层面因素

表1 理论分析框架表。

\begin{tabular}{|c|c|c|}
\hline $\begin{array}{l}\text { 新能源人才吸引 } \\
\text { 力 }\end{array}$ & $\begin{array}{l}\text { 地区层面吸引 } \\
\text { 力 } \\
\text { 行业层面吸引 } \\
\text { 力 } \\
\\
\text { 企业层面吸引 } \\
\text { 力 }\end{array}$ & $\begin{array}{l}\text { 自然环境影响 } \\
\text { 生活环境影响 } \\
\text { 文化环境影响 } \\
\text { 人才政策影响 } \\
\text { 行业薪酬福利影响 } \\
\text { 行业政府扶持影响 } \\
\text { 行业发展前景影响 } \\
\text { 企业福利影响 } \\
\text { 企业科研条件影响 } \\
\text { 企业激励体系影响 } \\
\text { 企业管理风格影响 } \\
\text { 企业工作特征影响 } \\
\text { 企业发展前途影响 }\end{array}$ \\
\hline
\end{tabular}

地区层面因素包括上述的自然环境影响、生活环境 影响、文化环境影响和人才政策的影响; 本节将影响因 素细分为对行业内科研人才、企业管理层与企业人力资 源总监进行调查。这些细分的因素包括上海的空气质量、 绿化程度、环境保护程度、医疗条件程度、居住条件、 交通便利程度、子女教育质量、生活节奏、工资水平、 物价水平、房屋价格、创新氛围、科研院校多少、公共 文化场所多少、文化氛围、政府对科研人才的重视程度、 科研人才子女落户难易程度、政府对科研人才实施的福 利水平等。

\subsection{2. 行业层面因素}

行业层面因素包括上述行业薪酬福利影响、行业政 府扶持影响和行业发展前景影响; 本节将影响因素细分 来对行业内科研人才、企业管理层与企业人力资源总监 进行调查。这些细分的因素包括行业福利水平、行业额 外奖励、行业政府扶持力度、行业落户难易程度、行业 未来前景、行业未来利润多少等。

\section{2. 3. 企业层面因素}

企业层面因素包括上述企业福利影响、企业科研条 件影响、企业激励体系影响、企业管理风格影响、企业 工作特征影响、企业发展前途影响。本节将影响因素细 分来对行业内科研人才、企业管理层与企业人力资源总 监进行调查。这些细分因素包括企业薪酬水平、企业福 利水平、企业假期安排、企业科研经费、企业实验设备、 企业提供同行交流机会、企业晋升制度、企业员工股利、 企业提供员工职业规划、企业对科研人才重视程度、企 业中科研人才沟通渠道、企业领导沟通机会、企业工作 节奏、企业工作自主性、企业工作压力、企业文化氛围、 企业知名度、企业实力、企业管理层能力。

\section{3. 研究方法及问卷编制}

\section{1. 研究方法与程序说明}

研究步骤如下所述, 一为问卷的编制, 二为数据的 收集, 三为数据的处理。

\section{2 . 问卷编制}

在问卷设计时, 考虑了新能源项目的问卷设计思路 [2] [3], 结合--研发人才吸引力现状及影响因素, 本文 将问卷设计为三个部分：1. 从研发人员角度的问卷设计; 2. 从企业管理人员角度的问卷设计; 3 . 从人力资源总监 角度的问卷设计。其中研发人员角度的问卷包括 4 个大项 89 个具体项 [4] [5], 企业管理人员角度的问卷包括3个大 项 37 个具体项，人力资源总监角度的问卷包括 6 个大项 20 个具体项。其中采用Liket5点量表法。其中 5 表示非常同 意或非常满意, 4 表示同意或满意, 3 表示中等或中立, 2 表示不同意或不满意, 1 表示非常不同意或非常不满意。 


\section{2. 1. 从研发人员角度的问卷设计}

对于科研人员来说, 科研人员到一个地方工作需要 进行三个层次的选择与比较, 从大到小的层次顺序为地 区层次的选择, 行业层次的选择以及企业层次的选择。 由于本文以上海市为样本来界定地区层次的选择, 以新 能源行业为样本来界定行业层次的选择, 因此选择上海 市新能源企业来进行抽样调查, 来探讨科研人员人才吸 引力现状以及影响因素较为合理。为了便于取样, 本次 调查选择现阶段一线的科研人员进行问卷调查, 以拿到 最终的统计结果进行对比分析。

为了便于结果分析，本文特地分析了被调查人员的 人员特征: 作为上海地区新能源行业的一线科研人员, 一般具有高学历水平, 高素质, 高科研能力等特征。另 外, 作为科研人员相对来讲男比女要多一些, 而且户籍 相对来讲外来人员也是一个影响因素。因此在做调查问 卷的时候同样把上述信息作为一个调查项目来填写。本 文将基本情况问卷设计草稿分为四个层次： 1. 一线科研 人员基本信息; 2 . 一线科研人员求学经历调查; 3 . 一线 科研人员工作经历调查; 4 . 一线科研人员单位情况调查 [7][10]。

\section{2. 2. 从企业管理人员角度的问卷设计}

同样对于管理层人员来说，他们对于科研人员的看 法和科研人员对自己的看法是有差别的, 因此在对科研 人员进行问卷调查之后需要对管理层的看法进行问卷调
查。与科研人员调查问卷类似, 管理层人员的问卷也分 为三个层次：地区层次的选择，行业层次的选择以及企 业层次的选择。当然, 管理层一般指的是主管级别而非 总监级别的管理层 $[9]$ 。

在进行结果分析时, 同样需要了解管理层被调查人 员的人员特征。相对于科研人员来讲, 管理层最大的特 征就是年龄梯度上普遍比科研人员要年长一些。另外学 历层次上要比科研人员相对更高一些。这与人们的经验 也正好相符。

\section{2. 3. 从人力资源总监角度的问卷设计}

对于人力资源总监来说, 本文只是从宏观的角度来 把控科研人员的信息。因此对于人力资源总监进行的调 查问卷就以人才的学历结构、职称结构、招工对象等等 来进行调查。

\section{3. 数据收集}

在本文的研究中, 被调查者为新能源行业的研发人 员，企业管理人员和企业人力资源总监。在问卷发放时 我们采用会谈和约谈的形式，与企业总监以及企业的人 力资源总监沟通的方式以保证回收率和有效问卷率。问 卷收集统计了 12 家新能源企业约 200 份科研人员问卷, 36 份管理人员问卷以及 10 分人力资源总监问卷。样本构成 如表1所示。

表 2 样本特征构成表。

\begin{tabular}{|c|c|c|c|c|c|}
\hline 项目 & 变量 & 科研人员人 数 & 比例 & 管理层人数 & 比例 \\
\hline \multirow{2}{*}{ 性别 } & 男 & 160 & $80 \%$ & 32 & $89 \%$ \\
\hline & 女 & 40 & $20 \%$ & 4 & $11 \%$ \\
\hline \multirow{5}{*}{ 工龄 } & 30岁及以下 & 78 & $39 \%$ & 1 & 2. $78 \%$ \\
\hline & 31岁-35岁 & 70 & $35 \%$ & 10 & $27.8 \%$ \\
\hline & 36岁-40岁 & 36 & $18 \%$ & 10 & $27.8 \%$ \\
\hline & 41岁-45岁 & 10 & $5 \%$ & 5 & $13.9 \%$ \\
\hline & 45岁以上 & 5 & $2.5 \%$ & 10 & $27.8 \%$ \\
\hline \multirow{2}{*}{ 籍贯 } & 上海 & 63 & $31.5 \%$ & 9 & $28.1 \%$ \\
\hline & 非上海 & 137 & $68.5 \%$ & 23 & $71.9 \%$ \\
\hline \multirow{5}{*}{ 学历 } & 专科 & 24 & $12.1 \%$ & 1 & 2. $78 \%$ \\
\hline & 本科 & 106 & $53.3 \%$ & 14 & $38.9 \%$ \\
\hline & 硕士 & 66 & $33.2 \%$ & 17 & $47.2 \%$ \\
\hline & 博士 & 3 & $1.5 \%$ & 4 & $11.1 \%$ \\
\hline & 博士后 & 0 & 0 & 0 & 0 \\
\hline \multirow{4}{*}{$\begin{array}{l}\text { 取得最高学历 } \\
\text { 城市 }\end{array}$} & 上海 & 78 & $39 \%$ & 20 & $55.6 \%$ \\
\hline & 内地其他城市 & 116 & $58 \%$ & 15 & $41.7 \%$ \\
\hline & 港澳台 & 2 & $1 \%$ & 0 & 0 \\
\hline & 海外 & 4 & $2 \%$ & 1 & $2.78 \%$ \\
\hline \multirow{2}{*}{$\begin{array}{l}\text { 是否有海外求 } \\
\text { 学经历 }\end{array}$} & 是 & 10 & $5 \%$ & 1 & $2.78 \%$ \\
\hline & 否 & 190 & $95 \%$ & 35 & $97.2 \%$ \\
\hline \multirow{5}{*}{ 专业职称 } & 初级职称 & 48 & $24 \%$ & & \\
\hline & 中级职称 & 47 & $23.5 \%$ & & \\
\hline & 副教授、副研究院或高级工程师 & 5 & $2.5 \%$ & & \\
\hline & 教授、研究员或教授级高级工程师 & 0 & 0 & & \\
\hline & 无职称 & 100 & $50 \%$ & & \\
\hline 合计 & & 200 & $100 \%$ & 36 & $100 \%$ \\
\hline
\end{tabular}




\section{4. 数据处理}

\section{1 . 信度分析和效度分析}

\subsection{1. 信度分析}

信度分析主要考察问卷的内部一致性系数, 本文中 采取Cronbach's a 系数测量, 对研究人员调查问卷的 66 个项目以及管理人员调查问卷的 18 个项目的数据进行 一致性进行检验。各个项目的 a 系数如下表所示。信度 整体而言相对较高。所以本研究的调查数据基本上处于 较好的信度水平。

表3 科研人员内部一致性系数。

\begin{tabular}{|c|c|c|c|c|}
\hline 项目 & & 题项数 & Cronbach's a & $\begin{array}{l}\text { 整体 } \alpha \\
\text { 系数 }\end{array}$ \\
\hline \multirow{5}{*}{$\begin{array}{l}\text { 城市吸 } \\
\text { 引力 }\end{array}$} & 城市自然环境 & 4 & 0.697 & \multirow{6}{*}{0.902} \\
\hline & 城市生活环境 & 9 & 0.731 & \\
\hline & 城市文化环境 & 5 & 0.820 & \\
\hline & 城市人才政策 & 5 & 0.774 & \\
\hline & 根植城市意愿 & 2 & 0.826 & \\
\hline & 行业福利状况 & 3 & 0.573 & \\
\hline 行业吸 & 行业政府扶持度 & 3 & 0.353 & \multirow{3}{*}{0.849} \\
\hline 引力 & 行业发展前景 & 3 & 0.643 & \\
\hline & 根植行业意愿 & 2 & 0.891 & \\
\hline 企业吸 & 企业福利状况 & 4 & 0.760 & 0.957 \\
\hline
\end{tabular}

\begin{tabular}{lllll}
\hline 项目 & & 题项数 & Cronbach' s a & $\begin{array}{c}\text { 整体 } \alpha \\
\text { 系数 }\end{array}$ \\
\hline 引力 & 企业科研条件 & 4 & 0.798 & \\
& 企业激励体系 & 3 & 0.468 & \\
& 企业管理风格 & 5 & 0.835 & \\
& 企业工作特征 & 4 & 0.781 & \\
& 企业发展前景 & 5 & 0.815 & \\
& 根植企业意愿 & 5 & 0.907 & \\
合计 & & 66 & & \\
\hline
\end{tabular}

表4 管理人员内部一致性系数。

\begin{tabular}{|c|c|c|}
\hline 项目 & 题项数 & Cronbach' $s \quad \alpha$ \\
\hline 城市吸引力 & 5 & 0.748 \\
\hline 行业吸引力 & 3 & 0.552 \\
\hline 企业吸引力 & 10 & 0.883 \\
\hline 合计 & 18 & \\
\hline
\end{tabular}

\subsection{2. 效度分析}

对于收到的问卷，用主成分分析法以特征根值大于 1 为 标准来截取数据。结果显示, KM0值为 0.895 , 巴特利特球 形度检验为 11281.017 , 相应的P概率接近 0 , 因此可以认为 相关系数矩阵不太会是单位矩阵, 变量适合做因子分析。 特征根值大于 1 的因子共 13 个, 累积方差贡献率为 $73.575 \%$, 可以解释原有变量的大部分信息, 运用方差最大法对因子 载荷矩阵实施正交旋转, 以使因子具有命名解释性。

表5 因子分析表。

\begin{tabular}{|c|c|c|c|c|c|}
\hline 因子(方差贡献) & 指标项 & 因子载荷 & 因子(方差贡献) & 指标项 & 因子载荷 \\
\hline \multirow{17}{*}{$\begin{array}{l}\text { 因子1 } \\
\text { 企业吸引力 } \\
(19.753 \%)\end{array}$} & 企业薪酬 & 0.645 & \multirow{3}{*}{$\begin{array}{l}\text { 因子 } 4 \\
\text { 城市人才政策（5.054\%） }\end{array}$} & 城市落户政策好 & 0.781 \\
\hline & 企业福利 & 0.769 & & 子女落户政策好 & 0.839 \\
\hline & 企业假期 & 0.718 & & 城市人才福利好 & 0.778 \\
\hline & 企业经费 & 0.748 & \multirow{3}{*}{$\begin{array}{l}\text { 因子5 } \\
\text { 行业发展前景（4.540\%） }\end{array}$} & 行业落户容易 & 0.612 \\
\hline & 企业实验设备 & 0.688 & & 行业有前景 & 0.618 \\
\hline & 同行交流机会 & 0.712 & & 行业未来利润高 & 0.782 \\
\hline & 晋升制度 & 0.803 & \multirow{6}{*}{$\begin{array}{l}\text { 因子6 } \\
\text { 对城市现状影响评价以及 } \\
\text { 城市根植愿望 }(4.345 \%)\end{array}$} & 上海自然环境影响 & 0.610 \\
\hline & 员工股权期权 & 0.692 & & 上海生活环境影响 & 0.610 \\
\hline & 企业职业规划 & 0.829 & & 上海文化环境影响 & 0.626 \\
\hline & 重视人才意见 & 0.795 & & 在上海工作是正确选择 & 0.509 \\
\hline & 提供沟通渠道 & 0.842 & & 继续在上海工作 & 0.663 \\
\hline & 与领导畅谈 & 0.707 & & 上海生活节奏适中 & 0.629 \\
\hline & 企业工作节奏 & 0.756 & \multirow{2}{*}{$\begin{array}{l}\text { 因子7 } \\
\text { 城市生活环境（3.954\%） }\end{array}$} & 上海物价适中 & 0.710 \\
\hline & $\begin{array}{l}\text { 企业工作自主性 } \\
\text { 企业工作压力 }\end{array}$ & $\begin{array}{l}0.709 \\
0.733\end{array}$ & & 上海房价适中 & 0.600 \\
\hline & 企业文化氛围 & 0.713 & & 上海空气质量好 & 0.623 \\
\hline & 行业福利影响 & 0.777 & 因于 8 & 上海城市绿化好 & 0.670 \\
\hline & 行业扶持影响 & 0.630 & \multirow{11}{*}{$\begin{array}{l}\text { 城市自然环境（3.318\%） } \\
\text { 因子 } 9 \\
\text { 城市创新氛围（3.136\%） } \\
\text { 因子10 } \\
\text { 城市文化创新氛围 } \\
\text { ( } 3.127 \%) \\
\text { 因子11 } \\
\text { 城市教育环境 }(3.114 \%) \\
\text { 因子12 } \\
\text { 行业根植愿望（2.513\%） } \\
\text { 因子13 } \\
\text { 行业政府扶持（1.835\%） }\end{array}$} & 上海环境保护好 & 0.811 \\
\hline \multirow{7}{*}{$\begin{array}{l}\text { 因子 } 2 \\
\text { 对行业现状以及企业 } \\
\text { 现状的影响评价 } \\
\text { (12.863\%) }\end{array}$} & 行业前景影响 & 0.753 & & 上海创新氛围好 & 0.695 \\
\hline & 企业福利影响 & 0.835 & & 上海科研院校多 & 0.626 \\
\hline & 科研条件影响 & 0.819 & & 上海公共文化场所多 & 0.658 \\
\hline & 企业激励影响 & 0.847 & & 上海文化氛围浓 & 0.522 \\
\hline & 管理风格影响 & 0.805 & & 上海子女教育条件好 & 0.757 \\
\hline & 工作特征影响 & 0.780 & & 在行业里工作是正确选择 & 0.559 \\
\hline & 企业前途影响 & 0.780 & & 会继续从事该行业 & 0.636 \\
\hline \multirow{3}{*}{$\begin{array}{l}\text { 因子 } 3 \\
\text { 企业根植愿望 } \\
(6.023 \%)\end{array}$} & 在当前企业工作正确与否 & 0.718 & & 政府对行业扶持力度大 & -0.487 \\
\hline & 当前企业工作朋友评价高 & 0.824 & & & \\
\hline & $\begin{array}{l}\text { 继续努力工作 } \\
\text { 有机会也不离开 }\end{array}$ & $\begin{array}{l}0.897 \\
0.918\end{array}$ & & & \\
\hline
\end{tabular}


企业薪酬, 企业福利, 企业假期, 企业经费, 企业实验 设备, 同行交流机会，晋升制度，员工股权期权，企业 职业规划, 重视人才意见, 提供沟通渠道, 与领导畅谈, 企业工作节奏，企业工作自主性，企业工作压力，企业 文化氛围这几个因素在第一个因子上有较高的载荷, 且 均为企业吸引力的影响因素, 因此将之称为企业吸引力。 后面以此类推, 这样可以命名得到 13 个因子。因子的名 称在表格中粗体字展示出来 [8]。

\section{5. 结论}

在通过统计分析和因子分析之后, 站在整体的角度 上来看, 对科技人员吸引力最大的因素是企业吸引力, 其次是对行业现状以及企业现状的影响评价、企业根植 愿望, 接下去是城市人才政策、行业发展前景、对城市 现状影响评价以及城市根植愿望、城市生活环境、城市 自然环境、城市创新氛围、城市文化氛围、城市生活环 境、行业根植愿望、行业政府扶持等等。

\section{6. 政策建议}

\section{1. 企业内部制度的完善是吸引人才的重要因素}

企业自身为吸引科技人才从事活动, 要不断加强自 身内部制度的完善。首先, 企业要给人才提供良好的发 展平台; 其次要完善内部工作科研环境, 鼓励创新以及 积极维护员工利益; 再次, 企业要制定相应的人才优惠 政策, 出台并落实政府提供的人才计划等鼓励其进入企 业。这样对物质与精神鼓励相结合, 使其吸引力发挥至 最大效用。

\section{2. 行业环境也是企业吸引人才的不可忽视的力量}

行业现状往往可以反映人才现状, 行业聚集往往也 有利于人才聚集, 良好的行业环境更能成为吸引科技人 才的力量。因此基于此原因, 政府应当通过改善行业发 展所需的基础设施来吸引企业, 并通过企业的发展, 带 动行业发展以及实现行业的升级, 最终达到吸引人才的 目的。

\section{3. 企业根植愿望使人才具有归属感}

由于企业在完善自身的同时, 也可以使企业内部的 科技人才提升其归属感。因此在企业完善内部制度时也 应注重企业文化的发展, 增强对人才的吸引力。

\section{参考文献}

[1] 王海芸, 宋镇. 企业高层次科技人才吸引力影响因素的实证 研究 $[J]$. 科学学与科学技术管理, 2011, 32 (3) : 152-157。

[2] 胡蓓, 周均旭, 翁清雄. 高科技产业集群特性对人才吸引力 的影响一一基于武汉光谷、北京中关村等产业集群的实证 $[J]$. 研究与发展管理, 2009, 21 (1) : 51-57。

[3] 周均旭, 胡蓓, 张西奎. 高科技产业集群人才吸引影响因素 的分层研究 [J]. 科技进步与对策, 2009, 26 (12) : 141-144。

[4] 胡蓓, 周均旭. 产业集群人才吸引力纵向分层研究一一以佛 山地区产业集群为例 [J]. 中国科技论坛, 2009 (1):94-97.

[5] 盛亚, 于卓灵. 浙江省科技人才集聚的政策效应 $[\mathrm{J}]$. 技术经 济, 2015(6):43-47。

[6] 苏津津, 杨柳. 天津市科技人才吸引影响因素研究 [J]. 科学 管理研究, 2013, 31 (3) : 109-112。

[7] 蔡宜旦. 浙东地区高学历青年人才区际流动行为及其影响 因素分析一一基于浙江宁波镇海区的实证调查 $[\mathrm{J}]$. 中国青 年研究, 2015 (6) :58-65。

[8］杨智勤. 组织吸引力在员工间的差异分析及其启示 [J]. 现 代管理科学, 2010(1): 54-56。

[9] 王养成. 企业人才吸引力及其定量评价研究 [J]. 工业技术 经济, 2006, 25 (12) :115-119。

[10] 王顺. 我国城市人才环境综合评价指标体系研究 [J]. 中国 软科学, 2004(3): 148-151。 